\title{
A comparison of the Gurevich et al. and the Liu-Jew wake models for the ion flux around a satellite
}

\author{
U. SAMIR \\ Department of Environmental Sciences, Tel-Aviv University, Israel and Space Physics Research \\ Laboratory, University of Michigan, Ann Arbor, Michigan, U.S.A. \\ M. FIRST \\ Department of Environmental Sciences, Tel-Aviv University, Israel. \\ E. J. Mater \\ Laboratory for Planetary Atmospheres, Goddard Space Flight Center, \\ Greenbelt, Maryland 20771, U.S.A. \\ and \\ B. Troy, JR. \\ E. O. Hulbort Conter for Space Research, \\ Naval Research Laboratory, Washington, D.C., 20375, U.S.A.
}

(Received 28 June 1973; in revised form 11 May 1974)

\begin{abstract}
Observations of ion currents obtained by a retarding potential analyzer on board the Explorer 31 Satellite were used to compare the Liu-Jew and Gurevich et al. wake models with experiment. The quantitative degree of agreement is shown and discussed. The Gurevich et al. 'neutral approximation' was tested via the observations and was found to be fairly good for regions where the hydrogen ions constitute more than 20 per cent of the plasma and the Mach number is low. For the case of high Mach number, tho Liu-Jew computations are in better agreement with the observations over the angle of attack range which could be studied, namely, $100^{\circ}-130^{\circ}$.
\end{abstract}

\section{IntroduCtion}

THE WIDE spectra of effects caused by a rapidly moving body (e.g. a spacecraft) in a rarefied plasma such as the ionosphere has attracted attention since the early 1960's. However, the amount of in situ observations relevant to various aspects of the interaction between an ionospheric satellite and its environmental plasma is still meagre. This situation is due mainly to the fact that no special 'wake' experiment was ever performed in situ. The data used were obtained as a by-product of experiments having other scientific objectives in mind. Also, most of the data refers to the angular distribution of electron current (i.e. $I_{b}=f\left(\theta_{i}\right)$ where $\theta_{i} \equiv$ angle of attack) and only fragmentary in situ information is available at present for ions.

Information for $I_{+}=f\left(\theta_{i}\right)$ at different distances from the surface of an ionospheric satellite is given by Hofrman (1967), Troy et al. (1970) and SAMIr et al. (1973), and to a much lesser extent by SAMIR and WILLMORE (1965). In the above papers $I_{+}$are given as $f\left(\theta_{i}\right)$ at $r \equiv R_{0}$, where $R_{0} \equiv$ satellite's effective radius and $r \equiv$ radial distance from the center of the satellite. Only Troy et al. (1970) give $I_{+}=\int\left(r / R_{0}\right)$ for one small set of observations. In addition to the fact that little in situ ion data are available, the measurements are performed aboard satellites of different size and geometry utilizing different experimental techniques and methods. The larger amount of data available from laboratory simulation measurements are still not adequately applicable to ionospheric satellites. 
The large number of theoretical sheath studies available and mainly the theoretical wake models do not seem to produce identical results although the same basic equations are used in the mathematical treatment. This is perhaps not surprising since the problem to be solved requires the self consistent solution of the Vlasov-Boltzmann and Poisson equations under realistic boundary conditions. To make the mathematical treatment more tractable simplifying assumptions are called upon, and the real physical or mathematical significance of the different assumptions is not always adequately evaluated.

A study in this direction has recently been initiated and some preliminary results (mainly for the electron angular distribution around a satellite) have been published (SAMIR and JEW (1972) and SAMIrR et al. (1973)).

This paper presents a comparison between the wake models of Liu and Jew (e.g. LIU, 1969) and Gurevich (e.g. GuREvich et al., 1970) using in situ measurements of ion flux performed on the Explorer 31 Satellite (Donley, 1969; SAMIR et al., 1973).

\section{The Experimental Data}

The Fxplorer 31 spacecraft was approximately cylindrical in shape having an 'effective' radius of about $40 \mathrm{~cm}$. The ion measurements used (Samir et al., 1973) were made by a planar retarding potential analyzer (RPA), mounted in the equatorial plane of the satellite with its aperture normal situated perpendicular to the satellite spin axis (DoNLEY, 1969; SAMIR et al., 1973). In that way a good coverage of ion flux (and density) as a function of the angle between the probe normal and the velocity vector $\left(v_{\varepsilon}\right)$ is obtained. Details of design, operation and data analysis are given elsewhere (DoNLEY, 1969).

For the purpose of the present study we have selected observations mainly in the altitude range $520-1100 \mathrm{~km}$. This covers a good range of ionospheric plasma parameters of interest. Namely,

$$
\begin{gathered}
16 \cdot 1 \leq R_{0} / \lambda_{D} \leq 114 \cdot 3 \\
2 \cdot 1 \leq\left|\Phi_{N}=\frac{e \Phi_{s}}{K T_{e}}\right| \leq 4 \cdot 1 \\
1 \cdot 2 \leq \mu\left(=\frac{v_{s}}{v_{T}(+)}\right) \leq 6 \cdot 8 \\
1 \cdot 00 \leq \frac{T_{e}}{T_{+}} \leq 1 \cdot 45 .
\end{gathered}
$$

$$
\text { Where } \begin{array}{ll}
R_{0} & \text { = effective radius of satellite } \\
\lambda_{D} & =\text { Debye length } \\
\Phi_{s} & =\text { satellite potential } \\
v_{s} & =\text { satellite velocity } \\
v_{T}(+) & =\text { ion thermal velocity computed for the mean ion mass } \\
T_{e} \text { and } T_{+} & =\text {electron and ion temperatures respectively } \\
\mu & =\text { velocity ratio (Mach number) }
\end{array}
$$


More detail on the specific values of each of the above parameters is given in SaMrr el al. (1973). The values given in (1) and in Table 1 should suffice for the comparison which is the subject of this paper.

Table 1. Some useful plasma parameters in the altitude range 520-1080 km. Values obtained from in situ observations

\begin{tabular}{|c|c|c|c|c|c|c|c|c|}
\hline \multirow[b]{2}{*}{$\begin{array}{l}\text { Pass } \\
\text { no. }\end{array}$} & \multirow[b]{2}{*}{$\begin{array}{c}\text { Altitude } \\
\text { range }(\mathrm{km})\end{array}$} & \multicolumn{2}{|c|}{$\begin{array}{c}\text { Ambient plasma } \\
\text { parameters }\end{array}$} & \multirow[b]{2}{*}{$\begin{array}{c}v_{8} \\
(\mathrm{~km} / \mathrm{sec})\end{array}$} & \multirow[b]{2}{*}{$\% \mathrm{H}^{+}$} & \multirow[b]{2}{*}{$\mu_{H}^{+}$} & \multirow[b]{2}{*}{$\mu$} & \multirow[b]{2}{*}{$\Phi_{N}$} \\
\hline & & $\begin{array}{c}N_{+}^{+} \\
\left(\times 10^{4} \mathrm{~cm}^{-3}\right)\end{array}$ & $\begin{array}{c}T_{e} \\
\left({ }^{\circ} \mathrm{K}\right)\end{array}$ & & & & & \\
\hline \multirow[t]{8}{*}{459} & $1081-990$ & $2 \cdot 4$ & 3117 & $7 \cdot 6$ & $44 \cdot 0$ & 1.06 & $2 \cdot 5$ & $-2 \cdot 1$ \\
\hline & $983-940$ & $2 \cdot 6$ & 2906 & $7 \cdot 6$ & $47 \cdot 0$ & $1 \cdot 10$ & $3 \cdot 0$ & $-2 \cdot 6$ \\
\hline & $933-885$ & $2 \cdot 8$ & 2897 & $7 \cdot 7$ & $37 \cdot 0$ & $1 \cdot 12$ & $\mathbf{3} \cdot \mathbf{3}$ & $-3 \cdot 0$ \\
\hline & $878-840$ & $3 \cdot 0$ & 2914 & $7 \cdot 7$ & $32 \cdot 0$ & $1 \cdot 11$ & $3 \cdot 6$ & $-3 \cdot 0$ \\
\hline & $834-791$ & $3 \cdot 2$ & 2989 & $7 \cdot 8$ & $25 \cdot 0$ & $1 \cdot 11$ & $3 \cdot 8$ & $-3 \cdot 6$ \\
\hline & $785-781$ & $3 \cdot 6$ & 2962 & $7 \cdot 8$ & $15 \cdot 0$ & $1 \cdot 12$ & $4 \cdot 0$ & $-3 \cdot 4$ \\
\hline & $745-709$ & $4 \cdot 4$ & 2933 & $7 \cdot 9$ & $13 \cdot 0$ & $1 \cdot 14$ & $4 \cdot 2$ & $-3 \cdot 3$ \\
\hline & $704-685$ & $5 \cdot 0$ & 2680 & $7 \cdot 9$ & $7 \cdot 5$ & & & \\
\hline \multirow[t]{5}{*}{482} & $909-830$ & $2 \cdot 7$ & 2700 & $7 \cdot 7$ & $44 \cdot 4$ & $1 \cdot 16$ & $\mathbf{3 \cdot 5}$ & $-3 \cdot 1$ \\
\hline & $824-782$ & $3 \cdot 0$ & 2880 & $7 \cdot 8$ & $29 \cdot 0$ & $1 \cdot 14$ & $3 \cdot 8$ & $-3 \cdot 1$ \\
\hline & $776-701$ & $3 \cdot 3$ & 3000 & $7 \cdot 9$ & $21 \cdot 0$ & $1 \cdot 13$ & $4 \cdot 0$ & $-3 \cdot 2$ \\
\hline & $696-634$ & $\mathbf{3} \cdot \mathbf{3}$ & 3250 & $7 \cdot 9$ & $12 \cdot 9$ & 1.08 & $4 \cdot 0$ & $-3 \cdot 2$ \\
\hline & $631-592$ & $3 \cdot 4$ & 3430 & $8 \cdot 0$ & $5 \cdot 2$ & 1.07 & $4 \cdot 1$ & $-3 \cdot 2$ \\
\hline \multirow[t]{3}{*}{683} & $567-539$ & $52 \cdot 0$ & 1337 & $8 \cdot 1$ & 0.0 & & $6 \cdot 8$ & $-3 \cdot 8$ \\
\hline & $537-529$ & $33 \cdot 0$ & 1511 & $8 \cdot 1$ & $0 \cdot 0$ & & $6 \cdot 4$ & $-4 \cdot 1$ \\
\hline & $527-521$ & $22 \cdot 0$ & 1742 & $8 \cdot 1$ & $0 \cdot 0$ & & $6 \cdot 0$ & $-3 \cdot 8$ \\
\hline
\end{tabular}

\section{The Theoretical Wake Models Used in this Study}

We compare the theoretical wake models of Liu-Jew (e.g. LrU, 1969) with the neutral approximation model of GUREVICH et al. (1970) and the neutral approximation equation used by SAMIR et al. (1973).

The Liu-Jew theory calculates the distribution of ion and electron densities $N_{+}{ }^{*}, N_{e}{ }^{*}$, normalized to the density in the ambient medium, and the distribution of the electrostatic potential $\Psi$, expressed in units of $k T_{+} / e$. The basic assumptions used in the theory are: (1) The body (e.g. a satellite) absorbs the electrons and neutralizes the ions that collide with it; the 'free stream' (i.e. ambient) plasma is considered to be in bithermal equilibrium with electron temperature $T_{\theta o}$ and ion temperature $T_{+0}$. (2) The charged particle mean free path is much larger than the body's characteristic linear dimension (say, its radius) which in turn is larger than the Debye length $\left(\lambda_{D}\right)$. (3) The flow is mesothermal, namely, $v_{T}(+) \ll v_{s} \ll v_{T}(e)$ where $v_{T}(+)$ and $v_{T}(e)$ are the ion and electron thermal velocities. (4) Magnetic field effects are not significant.

In this theory the Vlasov-Poisson system of equations is solved in a self consistent manner provided one accepts the approximate constant of motion $I_{8}$ introduced by Jew (JEw, 1968; LIU and JEw, 1968; LIU, 1969). The 'constancy' of this constant $I_{3}$, however, is still a matter of some controversy. The validity of the above constant of motion requires that the potential difference between 
adjacent points on the grid mesh used for the numerical calculations be small compared to the ion kinetic energy in the reference frame of the satellite. It is also assumed that for $\Phi_{s}$ negative the Boltzmann relationship holds in the near wake. More detail on this theory is given by LIU (1969) and some critical remarks on its use and the validity of the assumptions used is given in SAMIR and JEW (1972).

The appropriate Gurevich et al. wake model used here is discussed in great detail in GUREVICH et al. (1970). We refer to the part where the flow of the plasma is considered to be of a mixture of ions. This implies that the $\mathrm{H}^{+}$ions can constitute a significant portion of the ion flux in the wake zone even if in the unperturbed plasma they constitute a relatively small percentage of the total concentration. Gurevich states ". . . whereas $n\left(\mathrm{H}^{+}\right)^{*}>(1-5) \times 10^{-2}$ in the unperturbed ionospheric plasma, in the region of maximum rarefaction the hydrogen ions are in the majority. Therefore in all the cases considered in the present section the structure of the region of maximum rarefaction is determined by the hydrogen ions." For the case of the data presented in this paper the 'Mach number' for hydrogen ions $\mu\left(\mathrm{H}^{+}\right)=\left[v_{s} / \sqrt{\left(2 k T_{e} / M_{+}\right)}\right]$varies in the range 1.06-1.16 where $M_{+}$ is the mass of hydrogen. Gurevich states that from his theory for this situation the influence of the electric field on the motion of the ions is not very strong and can therefore be neglected. He further claims that when $n\left(\mathrm{H}^{+}\right)>20$ per cent it is justified to use the formulas of the neutral approximation. Then, using the assumption that in this approximation the different components of the plasma act independently, the expression for the plasma 'concentration' on the boundary of the region of maximum rarefaction is given (in the Gurevich notation for a two species plasma) by:

$$
\begin{aligned}
\rho= & n\left(\mathrm{O}^{+}\right)\left[\frac{\left[1+\operatorname{erf}\left(\mu\left(\mathrm{O}^{+}\right) \cos \phi_{0} \cos \theta\right)\right.}{1+\operatorname{erf}\left(\mu \mathrm{O}^{+}\right) \cos \theta_{0}}\right] \\
& +n\left(\mathrm{H}^{+}\right)\left[\frac{1+\operatorname{erf}\left(\mu\left(\mathrm{H}^{+}\right) \cos \phi_{0} \cos \theta\right)}{1+\operatorname{erf}\left(\mu\left(\mathrm{H}^{+}\right) \cos \theta_{0}\right)}\right]
\end{aligned}
$$

where $\phi_{0}$ is an angle characterizing the position of the boundary of the 'region of maximum rarefaction' and the $n$ 's are the relative ion concentrations. Expression (2) assumes a two species ion mixture namely, $\mathrm{H}^{+}$and $\mathrm{O}^{+}$only.

\section{Results and Discussion}

Table 1 presents the ambient values of the ion concentration $N_{+}$(in units of $10^{4} \mathrm{~cm}^{-3}$ ), the electron temperature $T_{e}\left(\right.$ in ${ }^{\circ} \mathrm{K}$ ), the satellite velocity $v_{s}$ (in $\mathrm{km} / \mathrm{sec}$ ), the percentage $\mathrm{H}^{+}\left(\% \mathrm{H}^{+}\right)$, the hydrogen Mach number $\mu\left(\mathrm{H}^{+}\right)$, the average Mach number $(\mu)$ calculated in the traditional way, and the normalized potential $\left(\Phi_{N}\right)$. More details about the measurements are given elsewhere (SAMIr et al., 1973).

Table 2 presents values of the normalized ion current (flux) for several angles $\theta$. The normalization was performed with respect to the current measured at $90^{\circ}$. The first row presents the values obtained from the analysis of the experimental

\footnotetext{
$* n\left(\mathrm{H}^{+}\right) \equiv$ relative concentration of the hydrogen ions.
} 
Table 2. Normalized ion currents for several angles of attack in the altitude range (520-1080) km. The normalization is with respect to $0=90^{\circ}$. (1) experimental; (2) theoretical-due to Gurevich et al.; (3) theoretical一due to Liu-Jew; (4) simplified neutral approximation used in Samir et al.

\begin{tabular}{|c|c|c|c|c|c|c|c|c|}
\hline $\begin{array}{c}\text { Pass } \\
\text { no. }\end{array}$ & $\begin{array}{c}\text { Altitude } \\
\text { range }(\mathrm{km})\end{array}$ & & $\frac{I(100)}{I(90)}$ & $\frac{I(115)}{I(90)}$ & $\frac{I(130)}{I(90)}$ & $\frac{I(145)}{I(90)}$ & $\frac{I(165)}{I(90)}$ & $\frac{I(180)}{I(90)}$ \\
\hline \multirow[t]{31}{*}{459} & \multirow[t]{4}{*}{$1081-990$} & (1) & $6 \cdot 7 \mathrm{E}-01$ & $4 \cdot 6 \mathrm{E}-01$ & $3 \cdot 2 \mathrm{E}-0 \mathrm{I}$ & $2 \cdot 6 \mathrm{E}-01$ & $2 \cdot 5 \mathrm{E}-01$ & \\
\hline & & (2) & $7 \cdot 2 \mathrm{E}-01$ & $4 \cdot 4 \mathrm{E}-01$ & $2 \cdot 9 \mathrm{E}-01$ & $2 \cdot 1 \mathrm{E}-01$ & $1 \cdot 6 \mathrm{E}-01$ & $1.5 \mathrm{E}-01$ \\
\hline & & (3) & $5 \cdot 2 \mathrm{E}-01$ & $5.4 \mathrm{E}-01$ & $4 \cdot 3 \mathrm{E}-01$ & $1 \cdot 6 \mathrm{E}-01$ & $1 \cdot 5 \mathrm{E}-02$ & $5 \cdot 0 \mathrm{E}-02$ \\
\hline & & (4) & $6 \cdot 1 \mathrm{E}-01$ & $8 \cdot 6 \mathrm{E}-02$ & $4 \cdot 5 \mathrm{E}-02$ & $2 \cdot 7 \mathrm{E}-02$ & $1 \cdot 6 \mathrm{E}-02$ & $1 \cdot 5 \mathrm{E}-02$ \\
\hline & \multirow[t]{4}{*}{$083-940$} & (1) & $6 \cdot 7 \mathrm{E}-01$ & $4 \cdot 6 \mathrm{E}-01$ & $3 \cdot 0 \mathrm{E}-01$ & $2 \cdot 2 \mathrm{E}-01$ & $2 \cdot 0 \mathrm{E}-01$ & \\
\hline & & (2) & $6 \cdot 8 \mathrm{E}-01$ & $3 \cdot 9 \mathrm{E}-01$ & $2 \cdot 7 \mathrm{E}-01$ & $2 \cdot 0 \mathrm{E}-01$ & $1 \cdot 5 E-01$ & $1 \cdot 4 \mathrm{E}-01$ \\
\hline & & (3) & $5 \cdot 2 \mathrm{E}-01$ & $5 \cdot 5 \mathrm{E}-01$ & $3 \cdot 9 \mathrm{E}-01$ & $9 \cdot 8 \mathrm{E}-02$ & $5 \cdot 1 E-03$ & $2 \cdot 3 \mathrm{E}-02$ \\
\hline & & (4) & $5 \cdot 9 \mathrm{E}-01$ & $8 \cdot 2 \mathrm{E}-02$ & $4 \cdot 4 \mathrm{E}-02$ & $2 \cdot 5 \mathrm{E}-02$ & $1 \cdot 5 \mathrm{E}-02$ & $1 \cdot 4 \mathrm{E}-02$ \\
\hline & \multirow[t]{4}{*}{$933-885$} & (1) & $6 \cdot 8 \mathrm{E}-01$ & $3 \cdot 4 \mathrm{E}-01$ & $2 \cdot 7 \mathrm{E}-01$ & $2 \cdot 5 \mathrm{E}-01$ & $1 \cdot 8 \mathrm{E}-01$ & \\
\hline & & (2) & $6 \cdot 4 \mathrm{E}-01$ & $3 \cdot 3 \mathrm{E}-01$ & $2 \cdot 1 \mathrm{E}-01$ & $1 \cdot 6 \mathrm{E}-01$ & $1 \cdot 2 \mathrm{E}-01$ & $1 \cdot 1 \mathrm{E}-01$ \\
\hline & & (3) & $5 \cdot 2 \mathrm{E}-01$ & $5 \cdot 5 \mathrm{E}-01$ & $3 \cdot 9 \mathrm{E}-01$ & $9 \cdot 8 \mathrm{E}-02$ & $5 \cdot 1 \mathrm{E}-03$ & $2 \cdot 3 \mathrm{E}-02$ \\
\hline & & (4) & $5 \cdot 5 \mathrm{E}-01$ & $6 \cdot 8 \mathrm{E}-02$ & $3 \cdot 6 \mathrm{E}-02$ & $2 \cdot 0 \mathrm{E}-02$ & $1 \cdot 2 \mathrm{E}-02$ & $1 \cdot 1 \mathrm{E}-02$ \\
\hline & \multirow[t]{4}{*}{$878-840$} & (1) & $7 \cdot 2 \mathrm{E}-01$ & $4 \cdot 6 \mathrm{E}-01$ & $3 \cdot 6 \mathrm{E}-01$ & $2 \cdot 7 \mathrm{E}-01$ & $2 \cdot 2 \mathrm{E}-01$ & \\
\hline & & (2) & $6 \cdot 0 \mathrm{E}-01$ & $2 \cdot 8 \mathrm{E}-01$ & $1 \cdot 8 \mathrm{E}-01$ & $1 \cdot 3 \mathrm{E}-01$ & $1 \cdot 0 \mathrm{E}-01$ & $9 \cdot 5 \mathrm{E}-02$ \\
\hline & & (3) & $5 \cdot 2 \mathrm{E}-01$ & $5 \cdot 5 \mathrm{E}-01$ & $3 \cdot 3 \mathbf{E}-01$ & $4 \cdot 3 \mathrm{E}-02$ & $6 \cdot 4 \mathrm{E}-04$ & $5 \cdot 5 \mathrm{E}-03$ \\
\hline & & (4) & $5 \cdot 2 \mathrm{E}-01$ & $6 \cdot 0 \mathrm{E}-02$ & $3 \cdot 2 \mathrm{E}-02$ & $1 \cdot 8 \mathrm{E}-02$ & $1 \cdot 1 \mathrm{E}-02$ & $9 \cdot 8 \mathrm{E}-03$ \\
\hline & \multirow[t]{4}{*}{$834-791$} & (1) & $1 \cdot 0 \mathrm{E}-01$ & $6 \cdot 3 \mathrm{E}-02$ & $4 \cdot 5 \mathrm{E}-02$ & $3 \cdot 4 \mathrm{E}-02$ & $2 \cdot 8 \mathrm{E}-02$ & \\
\hline & & (2) & $5 \cdot 7 \mathrm{E}-01$ & $2 \cdot 4 \mathrm{E}-01$ & $1 \cdot 5 \mathrm{E}-01$ & $1 \cdot 1 \mathrm{E}-01$ & $8 \cdot 3 E-02$ & $7 \cdot 8 \mathrm{E}-02$ \\
\hline & & (3) & $5 \cdot 2 \mathrm{E}-01$ & $5 \cdot 5 \mathrm{E}-01$ & $3 \cdot 3 \mathrm{E}-01$ & $4 \cdot 3 \mathrm{E}-02$ & $6 \cdot 4 \mathrm{E}-04$ & $5 \cdot 5 \mathrm{E}-03$ \\
\hline & & (4) & $4 \cdot 9 \mathrm{E}-01$ & $5 \cdot 3 \mathrm{E}-02$ & $2 \cdot 8 \mathrm{E}-02$ & $1 \cdot 6 \mathrm{E}-02$ & $9 \cdot 6 \mathrm{E}-03$ & $8 \cdot 5 \mathrm{E}-03$ \\
\hline & \multirow[t]{4}{*}{$785-781$} & (1) & $5 \cdot 5 \mathrm{E}-01$ & $3 \cdot 8 \mathrm{E}-01$ & $2 \cdot 9 \mathrm{E}-01$ & $1 \cdot 9 E-01$ & $1 \cdot 6 \mathrm{E}-01$ & \\
\hline & & (2) & $5 \cdot 2 \mathrm{E}-01$ & $1 \cdot 7 \mathrm{E}-01$ & $9 \cdot 2 \mathrm{E}-02$ & $6 \cdot 5 \mathrm{E}-02$ & $5 \cdot 0 \mathrm{E}-02$ & $4 \cdot 7 \mathrm{E}-02$ \\
\hline & & (3) & $5 \cdot 2 \mathrm{E}-0 \mathrm{I}$ & $5 \cdot 5 \mathrm{E}-01$ & $3 \cdot 3 \mathrm{E}-01$ & $4 \cdot 3 \mathrm{E}-02$ & $6 \cdot 4 \mathrm{E}-04$ & $5 \cdot 5 \mathrm{E}-03$ \\
\hline & & $(4)$ & $4 \cdot 0 \mathrm{E}-01$ & $3 \cdot 8 \mathrm{E}-02$ & $2 \cdot 0 \mathrm{E}-02$ & $1 \cdot 1 \mathrm{E}-02$ & $6 \cdot 7 \mathrm{E}-03$ & $5 \cdot 9 E-03$ \\
\hline & \multirow[t]{4}{*}{$745-709$} & (1) & $5 \cdot 0 \mathrm{E}-01$ & $3 \cdot 0 \mathrm{E}-01$ & $2 \cdot 0 \mathrm{E}-01$ & $1 \cdot 6 \mathrm{E}-01$ & $1 \cdot 2 \mathrm{E}-01$ & \\
\hline & & (2) & $4 \cdot 9 \mathrm{E}-01$ & $1 \cdot 3 \mathrm{E}-01$ & $6 \cdot 5 \mathrm{E}-02$ & $4 \cdot 7 \mathrm{E}-02$ & $3 \cdot 6 \mathrm{E}-02$ & $3 \cdot 4 \mathrm{E}-02$ \\
\hline & & (3) & $5 \cdot 2 \mathrm{E}-01$ & $5 \cdot 5 \mathrm{E}-01$ & $3 \cdot 3 \mathrm{E}-01$ & $4 \cdot 3 \mathrm{E}-02$ & $6 \cdot 4 \mathrm{E}-04$ & $5 \cdot 5 E-03$ \\
\hline & & (4) & $3 \cdot 5 \mathrm{E}-01$ & $3 \cdot 1 \mathrm{E}-02$ & $1 \cdot 6 \mathrm{E}-02$ & $9 \cdot 3 \mathrm{E}-03$ & $5 \cdot 5 \mathrm{E}-03$ & $4 \cdot 9 \mathrm{E}-03$ \\
\hline & \multirow[t]{3}{*}{$704-685$} & (1) & $4 \cdot 5 \mathrm{E}-01$ & $2 \cdot 9 \mathrm{E}-01$ & $1 \cdot 8 \mathrm{E}-01$ & $1 \cdot 3 E-01$ & $1.0 \mathrm{E}-01$ & \\
\hline & & $\begin{array}{l}(2) \\
(3)\end{array}$ & $4 \cdot 5 \mathrm{E}-0 \mathrm{I}$ & $9 \cdot 6 \mathrm{E}-02$ & $4 \cdot 1 \mathrm{E}-02$ & $2 \cdot 8 \mathrm{E}-02$ & $2 \cdot 2 \mathrm{E}-02$ & $2 \cdot 0 \mathrm{E}-02$ \\
\hline & & (4) & $2 \cdot 8 \mathrm{E}-01$ & $2 \cdot 3 \mathrm{E}-02$ & $1 \cdot 1 \mathrm{E}-02$ & $6 \cdot 2 \mathrm{E}-03$ & $3 \cdot 6 \mathrm{E}-03$ & $3 \cdot 1 \mathrm{E}-03$ \\
\hline \multirow[t]{4}{*}{482} & \multirow[t]{4}{*}{$909-830$} & (1) & $7 \cdot 3 \mathbf{E}-01$ & $3 \cdot 9 \mathrm{E}-01$ & $2 \cdot 5 \mathrm{E}-01$ & $1 \cdot 9 \mathrm{E}-01$ & $1 \cdot 7 E-01$ & \\
\hline & & (2) & $6 \cdot 3 \mathrm{E}-0 \mathrm{I}$ & $3 \cdot 3 \mathrm{E}-01$ & $2 \cdot 2 \mathrm{E}-01$ & $1 \cdot 7 \mathrm{E}-01$ & $1 \cdot 3 \mathrm{E}-01$ & $1 \cdot 2 \mathrm{E}-01$ \\
\hline & & (3) & $5 \cdot 2 \mathrm{E}-01$ & $5 \cdot 4 \mathrm{E}-01$ & $3 \cdot 5 \mathrm{E}-01$ & $5 \cdot 9 \mathrm{E}-02$ & $1 \cdot 5 \mathrm{E}-03$ & $9 \cdot 0 \mathrm{E}-03$ \\
\hline & & (4) & $5 \cdot 6 \mathrm{E}-01$ & $7 \cdot 1 \mathrm{E}-02$ & $3 \cdot 7 \mathrm{E}-02$ & $2 \cdot 1 \mathrm{E}-02$ & $1 \cdot 2 \mathrm{E}-02$ & $1 \cdot 1 \mathrm{E}-02$ \\
\hline
\end{tabular}


Table 2 (cont.)

\begin{tabular}{|c|c|c|c|c|c|c|c|c|}
\hline $\begin{array}{l}\text { Pess } \\
\text { no. }\end{array}$ & $\begin{array}{l}\text { Altitude } \\
\text { range }(\mathrm{km})\end{array}$ & & $\frac{I(100)}{I(90)}$ & $\frac{I(115)}{I(90)}$ & $\frac{I(130)}{I(90)}$ & $\frac{I(145)}{I(90)}$ & $\frac{I(165)}{I(90)}$ & $\frac{I(180)}{I(90)}$ \\
\hline & \multirow[t]{3}{*}{$824-782$} & (1) & $7 \cdot 3 \mathrm{E}-01$ & $3.9 \mathrm{E}-01$ & $2 \cdot 5 \mathrm{E}-01$ & $1 \cdot 9 \mathrm{E}-01$ & $1 \cdot 5 \mathrm{E}-01$ & \\
\hline & & (2) & $5 \cdot 7 \mathrm{E}-01$ & $2 \cdot 4 \mathrm{E}-01$ & $1 \cdot 5 \mathrm{E}-01$ & $1 \cdot 1 \mathrm{E}-01$ & $8 \cdot 9 \mathrm{E}-02$ & $8 \cdot 4 \mathrm{E}-02$ \\
\hline & & $\begin{array}{l}\text { (3) } \\
\text { (4) }\end{array}$ & $4.9 \mathrm{E}-01$ & $5 \cdot 5 E-02$ & $2 \cdot 9 \mathrm{E}-02$ & $1 \cdot 7 \mathrm{E}-02$ & $1.0 \mathrm{E}-02$ & $8 \cdot 8 \mathrm{E}-03$ \\
\hline & \multirow[t]{4}{*}{$776-701$} & (1) & $6 \cdot 2 \mathrm{E}-01$ & $3 \cdot 6 \mathrm{E}-01$ & $2 \cdot 6 \mathrm{E}-01$ & $2 \cdot 1 \mathrm{E}-01$ & $1 \cdot 3 E-01$ & \\
\hline & & (2) & $5 \cdot 4 \mathrm{E}-01$ & $2 \cdot 0 \mathrm{E}-01$ & $1 \cdot 1 \mathrm{E}-01$ & $8 \cdot 5 E-02$ & $6 \cdot 6 \mathrm{E}-02$ & $6 \cdot 2 \mathrm{E}-02$ \\
\hline & & (3) & $5 \cdot 1 \mathrm{E}-01$ & $5 \cdot 4 \mathrm{E}-01$ & $3 \cdot 1 \mathrm{E}-01$ & $3 \cdot 2 \mathrm{E}-02$ & $3 \cdot 5 \mathrm{E}-04$ & $2 \cdot 4 \mathrm{E}-03$ \\
\hline & & (4) & $4 \cdot 4 \mathrm{E}-01$ & $4 \cdot 6 \mathrm{E}-02$ & $2 \cdot 4 \mathrm{E}-02$ & $1 \cdot 4 \mathrm{E}-02$ & $8 \cdot 4 \mathrm{E}-03$ & $7 \cdot 4 \mathrm{E}-03$ \\
\hline & \multirow[t]{4}{*}{$696-634$} & (1) & $6 \cdot 1 \mathrm{E}-01$ & $3 \cdot 6 \mathrm{E}-01$ & $2 \cdot 7 \mathrm{E}-01$ & $1 \cdot 9 \mathrm{E}-01$ & $1 \cdot 4 \mathrm{E}-01$ & \\
\hline & & (2) & $5 \cdot 2 \mathrm{E}-0 \mathrm{I}$ & $1 \cdot 6 \mathrm{E}-01$ & $7 \cdot 8 \mathrm{E}-02$ & $5 \cdot 7 \mathrm{E}-02$ & $4 \cdot 5 E-02$ & $4 \cdot 2 E-02$ \\
\hline & & (3) & $5 \cdot 1 E-01$ & $5 \cdot 4 \mathrm{E}-01$ & $3 \cdot 1 \mathrm{E}-01$ & $3 \cdot 2 \mathrm{E}-02$ & $3 \cdot 5 \mathrm{E}-04$ & $2 \cdot 4 \mathrm{E}-03$ \\
\hline & & (4) & $3 \cdot 8 \mathrm{E}-01$ & $3 \cdot 6 \mathrm{E}-02$ & $1 \cdot 9 \mathrm{E}-02$ & $1 \cdot 1 \mathrm{E}-02$ & $7 \cdot 1 \mathrm{E}-03$ & $6 \cdot 3 \mathrm{E}-03$ \\
\hline & \multirow[t]{4}{*}{$631-592$} & (1) & $5 \cdot 7 \mathrm{E}-01$ & $3 \cdot 3 \mathrm{E}-01$ & $2 \cdot 4 \mathrm{E}-01$ & $2 \cdot 0 \mathrm{E}-01$ & $1 \cdot 6 \mathrm{E}-01$ & \\
\hline & & (2) & $4 \cdot 9 \mathrm{E}-01$ & $1 \cdot 2 E-01$ & $4 \cdot 2 \mathrm{E}-02$ & $2 \cdot 8 \mathrm{E}-02$ & $2 \cdot 2 \mathbf{E}-02$ & $2 \cdot 1 \mathrm{k}-02$ \\
\hline & & (3) & $5 \cdot 1 \mathrm{E}-01$ & $5 \cdot 4 \mathrm{E}-01$ & $3 \cdot 1 E-01$ & $3 \cdot 2 \mathrm{E}-02$ & $3 \cdot 5 E-04$ & $2 \cdot 4 \mathrm{E}-03$ \\
\hline & & (4) & $3 \cdot 0 \mathrm{E}-01$ & $2 \cdot 3 \mathrm{E}-02$ & $1 \cdot 2 \mathrm{E}-02$ & $7 \cdot 3 \mathrm{E}-03$ & $4 \cdot 5 \mathbf{E}-03$ & $4 \cdot 0 E-03$ \\
\hline \multirow[t]{12}{*}{683} & \multirow[t]{4}{*}{$567-539$} & (1) & $2 \cdot 0 \mathrm{E}-01$ & $7 \cdot 8 \mathrm{E}-02$ & $1 \cdot 7 \mathrm{E}-02$ & $4 \cdot 8 \mathrm{E}-03$ & & \\
\hline & & (2) & $2 \cdot 4 \mathrm{E}-01$ & $3 \cdot 9 \mathrm{E}-03$ & $1 \cdot 1 \mathrm{E}-05$ & $2 \cdot 2 \mathrm{E}-08$ & $4 \cdot 0 \mathrm{E}-11$ & $8 \cdot 2 \mathrm{E}-12$ \\
\hline & & (3) & $5 \cdot 0 \mathrm{E}-01$ & $5 \cdot 3 E-01$ & $1 \cdot 4 \mathrm{E}-01$ & $3 \cdot 8 \mathrm{E}-04$ & $1 \cdot 1 \mathrm{E}-09$ & $2 \cdot 3 E-08$ \\
\hline & & (4) & $4 \cdot 8 \mathrm{E}-02$ & $1 \cdot 0 \mathrm{E}-05$ & $8 \cdot 6 \mathrm{E}-11$ & $2 \cdot 1 \mathrm{E}-14$ & $1.0 \mathrm{E}-19$ & $4.4 \mathrm{E}-21$ \\
\hline & \multirow[t]{4}{*}{$537-529$} & (1) & $2 \cdot 5 \mathrm{E}-01$ & $6 \cdot 7 \mathbf{E}-02$ & $2 \cdot 3 E-02$ & & & \\
\hline & & (2) & $2 \cdot 6 \mathrm{E}-01$ & $6 \cdot 6 \mathbf{E}-03$ & $3 \cdot 6 \mathrm{E}-05$ & $1 \cdot 4 \mathrm{E}-07$ & $6 \cdot 3 \mathrm{E}-10$ & $1 \cdot 3 \mathrm{E}-10$ \\
\hline & & (3) & $5 \cdot 0 \mathrm{E}-01$ & $5 \cdot 3 \mathrm{E}-01$ & $1 \cdot 4 \mathrm{E}-01$ & $3 \cdot 8 \mathrm{E}-04$ & $1 \cdot 1 \mathrm{E}-09$ & $2 \cdot 3 E-08$ \\
\hline & & (4) & $6 \cdot 1 \mathrm{E}-02$ & $2 \cdot 6 \mathrm{E}-05$ & $7 \cdot 4 \mathrm{E}-10$ & $-1 \cdot 8 E-14$ & $1 \cdot 3 \mathrm{E}-17$ & $8 \cdot 1 \mathrm{E}-19$ \\
\hline & \multirow[t]{4}{*}{$527-521$} & (1) & $2 \cdot 1 \mathrm{E}-01$ & $4 \cdot 2 \mathrm{E}-02$ & $1 \cdot 2 \mathrm{E}-02$ & & & \\
\hline & & (2) & $3 \cdot 0 \mathrm{E}-01$ & $1 \cdot 1 \mathrm{E}-02$ & $1 \cdot 2 \mathrm{E}-04$ & $9 \cdot 3 \mathrm{E}-07$ & $7 \cdot 3 \mathrm{E}-09$ & $2 \cdot 1 \mathrm{E}-09$ \\
\hline & & (3) & $5 \cdot 0 \mathrm{E}-01$ & $5 \cdot 3 E-01$ & $1 \cdot 8 E-01$ & $1 \cdot 7 \mathrm{E}-03$ & $1 \cdot 2 \mathrm{E}-07$ & $1 \cdot 8 \mathrm{E}-06$ \\
\hline & & (4) & $7 \cdot 9 \mathrm{E}-02$ & $6 \cdot 4 \mathrm{E}-05$ & $6 \cdot 8 \mathrm{E}-09$ & $3 \cdot 9 \mathrm{E}-13$ & $1 \cdot 8 E-15$ & $1 \cdot 6 \mathrm{E}-16$ \\
\hline
\end{tabular}

data (Donlex, 1969; SAmrr et al., 1973). The second row represents the calculated values of $I(\theta) / I(90)$ following the Gurevich model discussed in the preceding section. The expression used here is basically (2) but modified to include the third component of ionic species $\mathrm{He}^{+}$. We used:

$$
\rho=\sum_{j=1}^{3}\left\{n(j)\left[\frac{1+\operatorname{erf}\left(\mu(j) \cos 45^{\circ} \cos \theta_{i}\right.}{1+\operatorname{erf}\left(\mu(j) \cos 45^{\circ}\right.}\right]\right\}
$$

where $j=1$ represents $\mathrm{H}^{+}$

$j=2$ represents $\mathrm{He}^{+}$

$j=3$ represents $0^{+}$.

The third row represents the results for currents (or fluxes) obtained employing an extended version of the Liu-Jew model which allows computation of fluxes as well as densities. The fourth row represents the results (for flux) obtained using the 
expression:

$$
\rho=\frac{\mathrm{N}\left(\mathrm{H}^{+}\right) F(\theta, 1)+\mathrm{N}\left(\mathrm{H}_{e}^{+}\right) F(\theta, 4)+\mathrm{N}\left(\mathrm{O}^{+}\right) F(\theta, 16)}{\mathrm{N}\left(\mathrm{H}^{+}\right)+\mathrm{N}\left(\mathrm{H}_{e}^{+}\right)+\mathrm{N}\left(\mathrm{O}^{+}\right)}
$$

whore: $F\left(\theta, M_{+}\right)=F\left(\mu \cos \theta_{i}\right) / F_{0}(\mu)$ (see SAMIn et al., 1973).

Expressions (4) and (3) are similar but not identical. While (3) in its final form includes the $\cos \phi_{0}$ term which does not appear in (4), expression (3) does not consider in its final form the thermal component of the ion velocity. This term is included in (4). Both (3) and (4) assume that separate ion species are non-interacting.

The fourth row is included to serve as an estimate to the contribution of the thermal component term in the absence of electric fields. This study extends the earlier studies of SAMIIR and JEW (1972), GUREvICH et al. (1970) (the section on theory/experiment comparison), and SAMTR et al. (1973), and can be seen as a complementary study to the above. The main comparison in this study is between the Liu-Jew and the Gurevich et al. theoretical wake models and the experimental data.

From Table 2 and Fig. 1(a) we see that for the higher altitudes in our sample, namely, at the altitude of $1081-940 \mathrm{~km}$, the Gurevich et al. neutral approximation
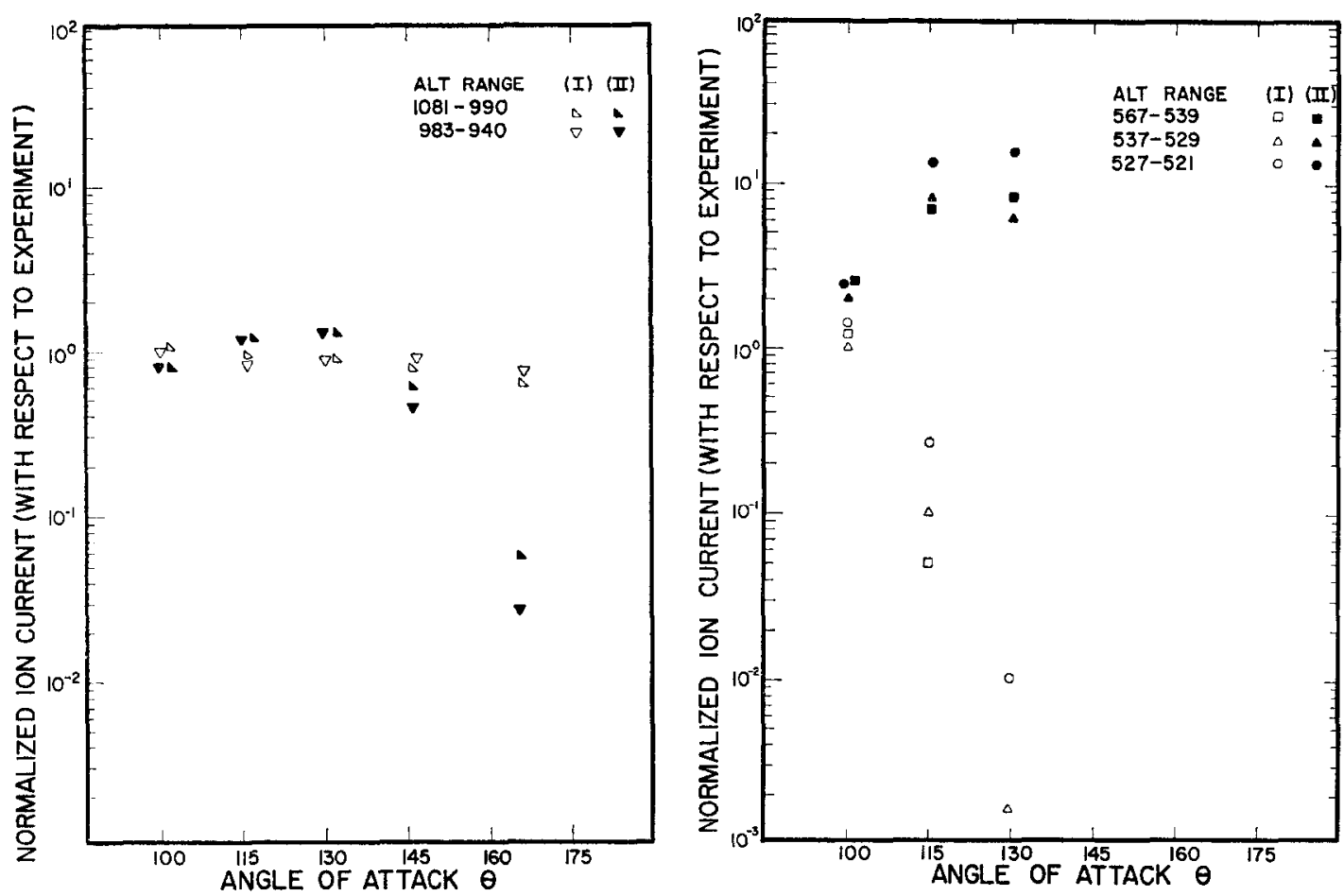

Fig. 1. Comparison of the Gurevich et al. and the Liu-Jew wake models with respect to the experimentel data in the angular range $100^{\circ}<\theta<165^{\circ}$. (a) For the altitude range $940-1081 \mathrm{~km}\left(100^{\circ}<\theta<165^{\circ}\right)$. (b) For the altitude range $521-567 \mathrm{~km}\left(100^{\circ}<\theta<130^{\circ}\right)$.

Note: I and II correspond to the GuREvich et al. (1970) theory and the LrU-JeW (1969) theory respectively. 
theory comes closest to the observations yielding values which are for all angles (except at $\theta=100^{\circ}$ ) lower than the experimental values. The ordinate of Fig. $1(a)$ is the ratio of the theoretical values from both theories divided by the corresponding experimental ones, the normalization being with respect to $\theta=90^{\circ}$ for both theory and experiment. For example the difference between the experimental values and those due to Gurevich (see rows (1) and (2) in Table 2 for this altitude range) is about 5 per cent at $\theta=115^{\circ}$ and 50 per cent at $\theta=165^{\circ}$, yielding some feel for the degree of applicability of the theory in the more rarefied part of the wake (i.e. going to higher angles, $\theta_{i}$ ). We conclude that the deviation of theory and experiment becomes more significant as the angle $\theta$ increases from $90^{\circ}$ towards $180^{\circ}$ and that the Gurevich model is still closer to the experimental values than the Liu-Jew model (see Fig. 1(a)). No experimental data are available for the maximum-wake angular position (i.e. $\theta=180^{\circ}$ ) but the Gurevich et al. model predicts a flux ratio three times that predicted by the Liu-Jew model for this angle, while the comparison at $\theta=165^{\circ}$ results in a difference of an order of magnitude. Comparing the Gurevich et al. neutral approximation with the one used by Samir et al. shows: $\rho(180)$ (Gurevich et al.) $\approx 10 \rho(180)$ (Samir et al.).

It is unfortunate that for perigee altitudes (i.e. $\approx 520-570 \mathrm{~km}$ ) the experimental data do not yield ion flux values for angles larger than $\theta=130^{\circ}$. This prevents a theory/experiment comparison for the maximum rarefaction regions. However, if we examine the situation for $100^{\circ} \leq \theta \leq 130^{\circ}$ in the altitudes $521-567 \mathrm{~km}$ we find that the values according to the Liu-Jew model come closer to the experimental results, as shown in Fig. $1(\mathrm{~b})$ and Table 2. This is most pronounced at $\theta=130^{\circ}$ where the computed results due to Gurevich et al. differ grossly from the experimental results. This may not be very surprising since in this altitude range $\mathrm{O}^{+}$is the primary ionic constituent as seen in Table 1. This implies that the neutral approximation breaks down, which is in accord with the GuRevich et al. (1970) prediction for the case $\left[\mathrm{H}^{+}\right]=0$ per cent and $\theta>120^{\circ}$. For $\theta<120^{\circ}$ the neutral approximation according to Gurevich is again valid, namely, his results are closer to the experimental ones (see Fig. $1(\mathrm{~b})$ at $\theta=100^{\circ}$ ). Selecting for example the altitude range of $776-701 \mathrm{~km}$ (which is intermediate between the altitude ranges already discussed) for further comparison where $\left[\mathrm{H}^{+}\right]=21$ per cent and examining the situations at $\theta=165^{\circ}$, we find the neutral approximation values to be closer to the experimental data compared with the values to the Liu-Jew model. This is in agreement with the Gurevich et al. statement that their theory should be a good approximation if $\left[\mathrm{H}^{+}\right]>20$ per cent (see Table 1). A behavior similar to the above is also seen at $\theta=145^{\circ}$. At angles smaller than $\theta=145^{\circ}$ i.e. at $\theta=130^{\circ}, 115^{\circ}, 100^{\circ}$ (see Table 2) the Liu-Jew and the neutral approximation used by Samir et al. are closer to the experimental data. However the maximum deviation of the theories from the experimental data is less than a factor of $2 \cdot 5$. If we further examine the situation at the altitude range $983-940 \mathrm{~km}$ where $\left[\mathrm{H}^{+}\right]=47$ per cent (the highest percentage of $\mathrm{H}^{+}$in the samples plotted) we find the values obtained from the Gurevich et al. model to be (generally) the closest to the experimental data. This is in accord with Gurevich et al. predictions. 


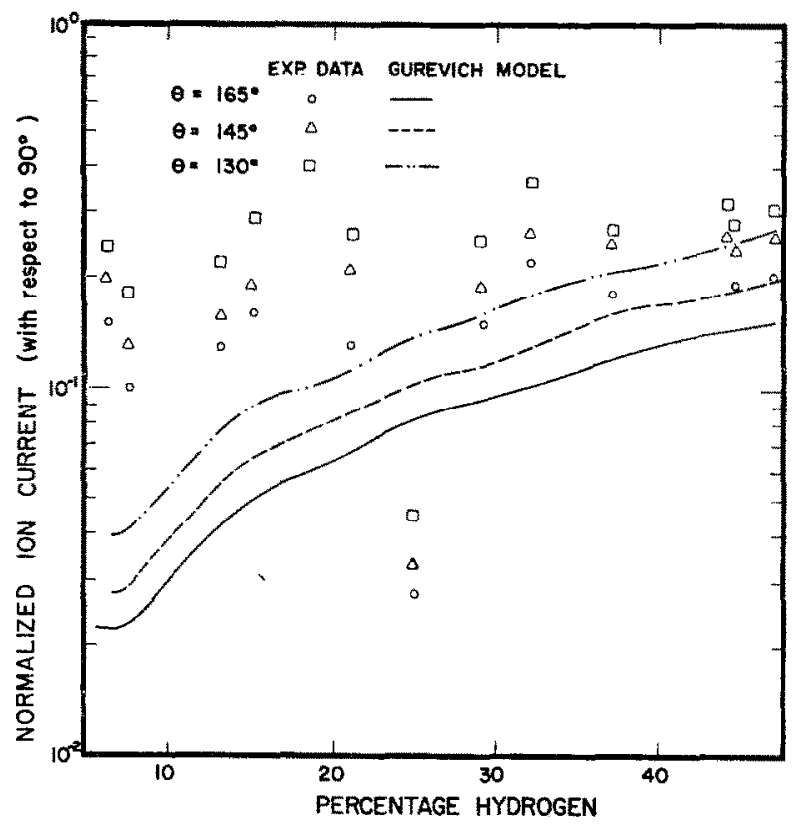

Fig. 2. Normulized ion current (with respect to the current at $90^{\circ}$ ) vs. percentage hydrogen for several angles of attack $(\theta)$ in the altitude range $(590-930 \mathrm{~km})$. Thick lines represent the GURwich et al. (1970) neutral approximation theory and the points represent the experimental values.

Figure 2 shows the normalized ion current as a function of percentage hydrogen for both the Gurevich et al. model and the experimental data. The normalization is with respect to $\theta=90^{\circ}$. Employing such a procedure gives the $\mathrm{O}^{+}$and/or other heavy ionic constituents different significance compared with the case of normalization with respect to $\theta=0^{\circ}$. For instance while $\left(\mathrm{H}^{+}\right)$may be as small as $(0.01-0.05)$ of the ambient plasma the $\mathrm{H}^{+}$ions dominate the region of maximum rarefaction (see also discussion in GuREvich et al., 1970). Figure 2 shows in great detail the domain (in terms of percentage $\mathrm{H}^{+}$) where the 'neutral approximation' is mostly applicable. It is clearly seen that for increasing percentage $\mathrm{H}^{+}$in the domain $(30-47)$ percentage $\mathrm{H}^{+}$the values obtained in the experiment are very close to the theoretical ones. Additional data (not plotted here) confirm the trend of the function for $\left[\mathrm{H}^{+}\right]$in the range $50-100$ per cent.

In summary, ion flux observations from an RPA on board Explorer 31 were compared with flux computations based on the theoretical wake models of Gurevich et al. and Liu-Jew. It was found that the Gurevioh oomputations better represent the observations for the case of low Mach number (also for percentage $\mathrm{H}^{+} \geq 20$ per cent). For the case of high Mach number, the Liu-Jew computations are in better agreement with the observations. A more comprehensive evaluation of the various theoretical wake models should include comparisons over a more complete range of the parameters as well as the mapping of the critical parameters throughout the entire perturbed region. It has not yet been possible to perform such systematic parametric studies. 
Acknowledgement-One of the authors (U.S.) wishes to acknowledge the support of NASA Grant NGR-23-005-320.

DONLEY J. L.

Gurevich A. V., Pitaevskin L. P. and Smirnova $V$.

HoHTMAN J. H.

HofFMan J. H.

LIU V. C.

SAMIR U. and WIILMORE A. P.

SAMIR U. and Jew H.

Samir U., Mamer E. J. and Troy B.

Troy B. E., Medved D. B. and SAMIR U.

\section{REFERENCES}

1969 Proc. IEEE 57, 1061.

1970 Soviet Physics-Uspekhi, 12, 595.

1967 Science 155, 322.

1969 Proc. $I E E E$ 57, 1063.

1969 Space Sci. Rev. 9, 423.

1965 Planet Space Sci. 13, 285.

$1972 J$ J.geophys. Res. 77, 6819.

1973 J. atmos. terr. Phys. 35, 513.

$1970 \quad J$. astron. Sci. 18, 173.

Reference is also made to the following unpublished material:

JEw $\mathbf{H}$.

LrU V. C. and JEw H.
1968 Ph.D. thesis, University of Michigan, Ann Arbor., Michigan.

1968 Paper No. 68-169, ATAA. 